\title{
Non-contiguous finished genome sequence and description of Clostridium dakarense sp. nov.
}

\author{
Cheikh Ibrahima Lo ${ }^{1}$, Ajay Kumar Mishra ${ }^{1}$, Roshan Padhmanabhan',Bissoume Samb Ba $^{2}$, \\ Amy Gassama Sow ${ }^{2}$, Catherine Robert ${ }^{1}$, Carine Couderc ${ }^{1}$, Ngor Faye ${ }^{3}$, Didier Raoult ${ }^{1}$, \\ Pierre-Edouard Fournier ${ }^{1}$, and Florence Fenollar ${ }^{*}$ \\ ${ }^{1}$ Aix-Marseille Université, Unité de Recherche sur les Maladies Infectieuses et Tropicales \\ Emergentes (URMITE), Marseille, France \\ ${ }^{2}$ Unité de Bactériologie Expérimentale Institut Pasteur de Dakar 36, Dakar, Senegal \\ ${ }^{3}$ Université Cheikh Anta Diop de Dakar, Laboratoire de Parasitologie générale, Fann \\ (Senegal)
}

*Correspondence: Florence Fenollar (florence.fenollar@univ-amu.fr)

Keywords: Clostridium dakarense, genome, culturomics, taxono-genomics

Clostridium dakarense strain FF1, is the type strain of Clostridium dakarense sp. nov., a new spe-
cies within the genus Clostridium. This strain, whose genome is described here, was isolated from
the fecal flora of a 4 -month-old Senegalese child suffering from gastroenteritis. C. dakarense sp.
nov. strain FF1 is an obligate anaerobic Gram-positive bacillus. Here we describe the features of
this organism, together with the complete genome sequence and annotation. The $3,735,762 \mathrm{bp}$
long genome (1 chromosome but no plasmid) exhibits a G+C content of $27.98 \%$ and contains
3,843 protein-coding and 73 RNA genes, including 8 rRNA genes.

\section{Introduction}

Clostridium dakarense strain FF1 ${ }^{\mathrm{T}}$ (= CSUR P243 = DSM 27086), is the type strain of Clostridium dakarense sp. nov. This bacterium is a Grampositive, anaerobic, spore-forming, indole negative bacillus that was isolated from the stool of a 4-month-old Senegalese child suffering from gastroenteritis as part of a "culturomics" study aiming at cultivating individually all species within human feces.

The elevated cost and lack of intra- and interlaboratory reproducibility of the "gold standard" of taxonomic tools. i.e. DNA-DNA hybridization and $\mathrm{G}+\mathrm{C}$ content determination [1], put bacterial taxonomic classification in a precarious state. In addition, the internationally-validated cutoff values of 16S rRNA sequence comparison [2] do not apply to all validly published genera and species. Recently, high throughput genome sequencing and mass spectrometric analyses of bacteria have allowed unprecedented access to a wealth of genetic and proteomic information [3]. As a consequence, we proposed to use a polyphasic approach [4] to describe new bacterial taxa, including genome sequence, MALDI-TOF spectrum and main phenotypic characteristics [5-11].

The genus Clostridium (Prazmowski, 1880), classified among the Firmicutes, was created in 1880 [12] and consists of obligate anaerobic rod-shaped bacilli capable of producing endospores [12]. More than 180 Clostridium species have been described to date [13]. Members of the genus Clostridium are mostly environmental bacteria or associated with the commensal digestive flora of mammals, but several are major human pathogens, including C. botulinum, C. difficile, C. tetani and $C$. perfringens $[14,15]$. A few species, such as $C$. butyricum and C. pasteurianum, fix nitrogen and have gained importance in agricultural and industrial applications [16,17].

Here we present a summary classification and a set of features for $C$. dakarense sp. nov. strain FF1 (= CSUR P243 = DSM 27086) together with the description of the complete genomic sequencing and annotation. These characteristics support the circumscription of the species $C$. dakarense sp. nov. 


\section{Classification and features}

A stool specimen was collected from a 4-month-old Senegalese child suffering from gastroenteritis. Informed consent was obtained from the child's parents and approval from the ethics committee from the Institut Federatif de Recherche 48 (Faculté de Médecine, Marseille, France). The fecal specimen was preserved at $-20^{\circ} \mathrm{C}$ after collection and sent to Marseille. Strain $\mathrm{FF}^{\mathrm{T}}$ (Table 1) was isolated in July 2011 by anaerobic cultivation on 5\% sheep bloodenriched Columbia agar (BioMerieux, Marcy
l'Etoile, France). This strain exhibited a 96.90\% 16S rRNA nucleotide sequence similarity with $C$. lituseburense, the phylogenetically closest validated Clostridium species (Figure 1). Although sequence similarity of the $16 \mathrm{~S}$ rRNA is not uniform across taxa, this value was lower than the $98.7 \%$ threshold recommended by Stackebrandt and Ebers to delineate a new species without carrying out DNA-DNA hybridization [30]. In addition, it was consistent with 16S rRNA identity values observed among validated species within the Clostridium genus that range from 78.4 to $99.8 \%$.

Table 1. Classification and general features of Clostridium dakarense strain $\mathrm{FF} 1^{\top}$ according to the MIGS recommendations [18].

\begin{tabular}{|c|c|c|c|}
\hline MIGS ID & Property & Term & Evidence code $^{\mathrm{a}}$ \\
\hline & \multirow{8}{*}{ Current classification } & Domain Bacteria & TAS [19] \\
\hline & & Phylum Firmicutes & TAS [20-22] \\
\hline & & Class Clostridia & TAS $[23,24]$ \\
\hline & & Order Clostridiales & TAS $[25,26]$ \\
\hline & & Family Clostridiaceae & TAS $[25,27]$ \\
\hline & & Genus Clostridium & TAS $[12,25,28]$ \\
\hline & & Species Clostridium dakarense & IDA \\
\hline & & Type strain FF1 & IDA \\
\hline & Gram stain & Positive & IDA \\
\hline & Cell shape & Rod-shaped & IDA \\
\hline & Motility & Motile & IDA \\
\hline & Sporulation & Sporulating & IDA \\
\hline & Temperature range & Mesophile & IDA \\
\hline & Optimum temperature & $37^{\circ} \mathrm{C}$ & IDA \\
\hline MIGS-6.3 & Salinity & Growth in $\mathrm{BHI}$ medium $+5 \% \mathrm{NaCl}$ & IDA \\
\hline \multirow[t]{3}{*}{ MIGS-22 } & Oxygen requirement & Anaerobic & IDA \\
\hline & Carbon source & Unknown & NAS \\
\hline & Energy source & Unknown & NAS \\
\hline MIGS-6 & Habitat & Human gut & IDA \\
\hline MIGS-15 & $\begin{array}{l}\text { Biotic relationship } \\
\text { Pathogenicity } \\
\text { Biosafety level }\end{array}$ & $\begin{array}{l}\text { Free living } \\
\text { Unknown } \\
2\end{array}$ & IDA \\
\hline MIGS-14 & Isolation & Human feces & NAS \\
\hline MIGS-4 & Geographic location & Senegal & IDA \\
\hline MIGS-5 & Sample collection time & June 2011 & IDA \\
\hline MIGS-4.1 & Latitude & 13.7167 & IDA \\
\hline MIGS-4.1 & Longitude & -16.4167 & IDA \\
\hline MIGS-4.3 & Depth & Surface & IDA \\
\hline MIGS-4.4 & Altitude & $51 \mathrm{~m}$ above sea level & IDA \\
\hline
\end{tabular}

aEvidence codes - IDA: Inferred from Direct Assay; TAS: Traceable Author Statement (i.e., a direct report exists in the literature); NAS: Non-traceable Author Statement (i.e., not directly observed for the living, isolated sample, but based on a generally accepted property for the species, or anecdotal evidence). These evidence codes are from the Gene Ontology project [29]. If the evidence is IDA, then the property was directly observed for a live isolate by one of the authors or an expert mentioned in the acknowledgements. 


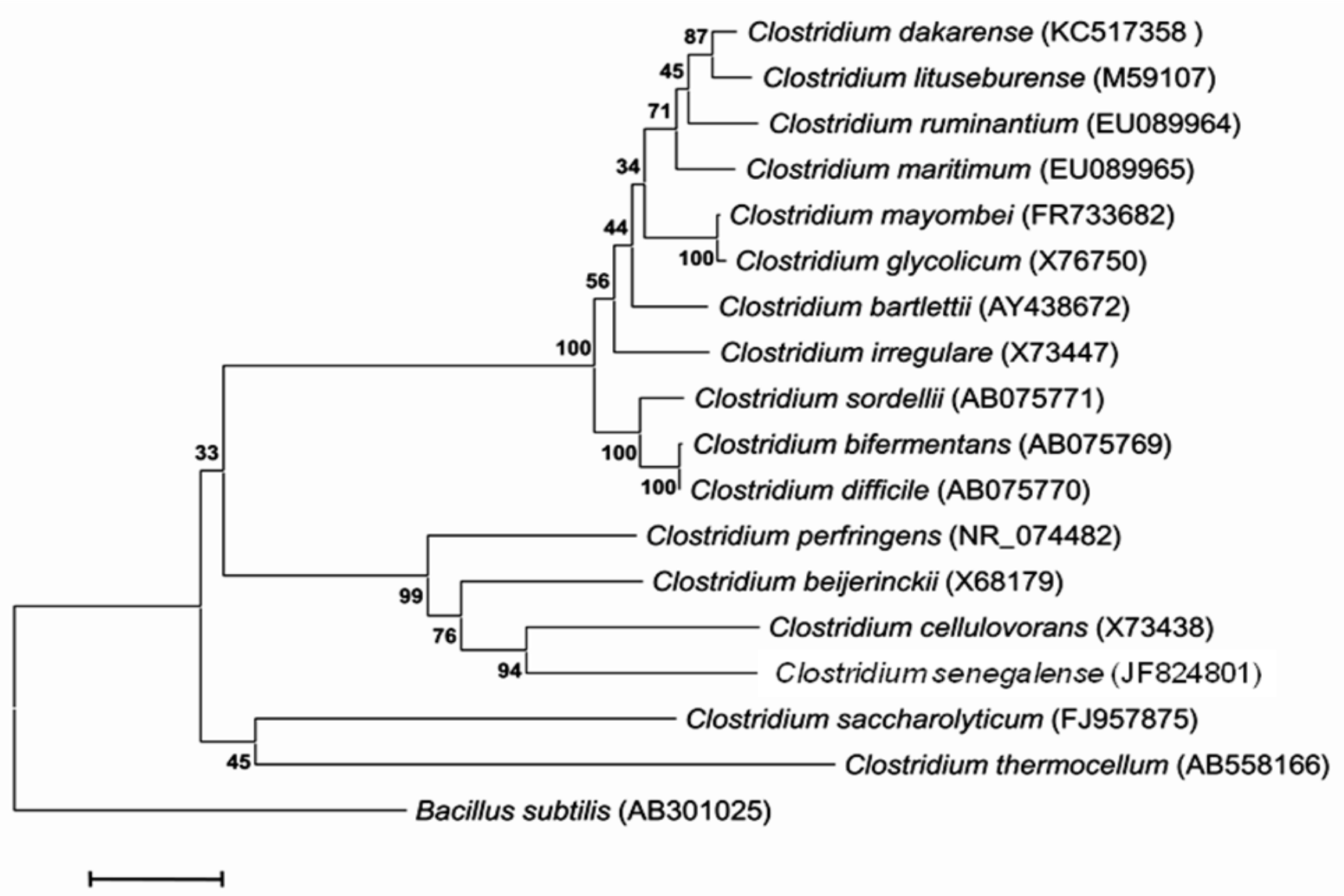

Figure 1. Phylogenetic tree highlighting the position of $C$. dakarense sp. nov. strain $\mathrm{FF} 1^{\top}$ relative to other type strains within the Clostridium genus. GenBank accession numbers are indicated in parentheses. Sequences were aligned using CLUSTALW, and phylogenetic inferences obtained using the maximum-likelihood method within the MEGA software. Numbers at the nodes are bootstrap values obtained by repeating 500 times the analysis to generate a majority consensus tree. Bacillus subtilis was used as an outgroup. The scale bar represents a $2 \%$ nucleotide sequence divergence.

Different growth temperatures $(25,30,37,45$ and $56^{\circ} \mathrm{C}$ ) were tested. Growth was observed between 25 and $37^{\circ} \mathrm{C}$, with optimal growth at $37^{\circ} \mathrm{C}$ after 24 hours of inoculation in anaerobic conditions. Colonies were $1.5 \mathrm{~mm}$ in diameter and opaque and smooth appearance on blood-enriched Columbia agar. Growth of the strain was tested under anaerobic and microaerophilic conditions using GENbag anaer and GENbag microaer systems, respectively (BioMerieux), and under aerobic conditions, with or without $5 \% \mathrm{CO}_{2}$. The strain growth was obtained only in anaerobic conditions. Gram staining showed rod-shaped Gram-positive bacilli able to form spores (Figure 2). The motility test was positive. Cells grown on agar have a mean diameter of $1.2 \mu \mathrm{m}$ (Figure 3).

Strain FF1 ${ }^{\mathrm{T}}$ exhibited neither catalase nor oxidase activities. Using API Rapid ID 32A (BioMerieux, Marcy l'Etoile), a positive reaction were observed for arginine dihydrolase, N-acetyl- $\beta$-glucosaminidase and pyroglutamic acid arylamidase. Negative reactions were observed for urease, indole and nitrate reduction. Using API $50 \mathrm{CH}$ (BioMerieux, Marcy l'Etoile), positive reactions were observed for galactose, glucose, maltose and saccharose fermentation and negative reaction were observed for ribose, lactose and fructose. $C$. dakarense is susceptible to amoxicillin, metronidazole, vancomycin, imipenem and rifampicin and resistant to trimethoprim/ sulfamethoxazole. When compared with representative species from the genus Clostridium, C. dakarense strain $\mathrm{FF} 1^{\mathrm{T}}$ exhibited the phenotypic differences detailed in Table 2. 


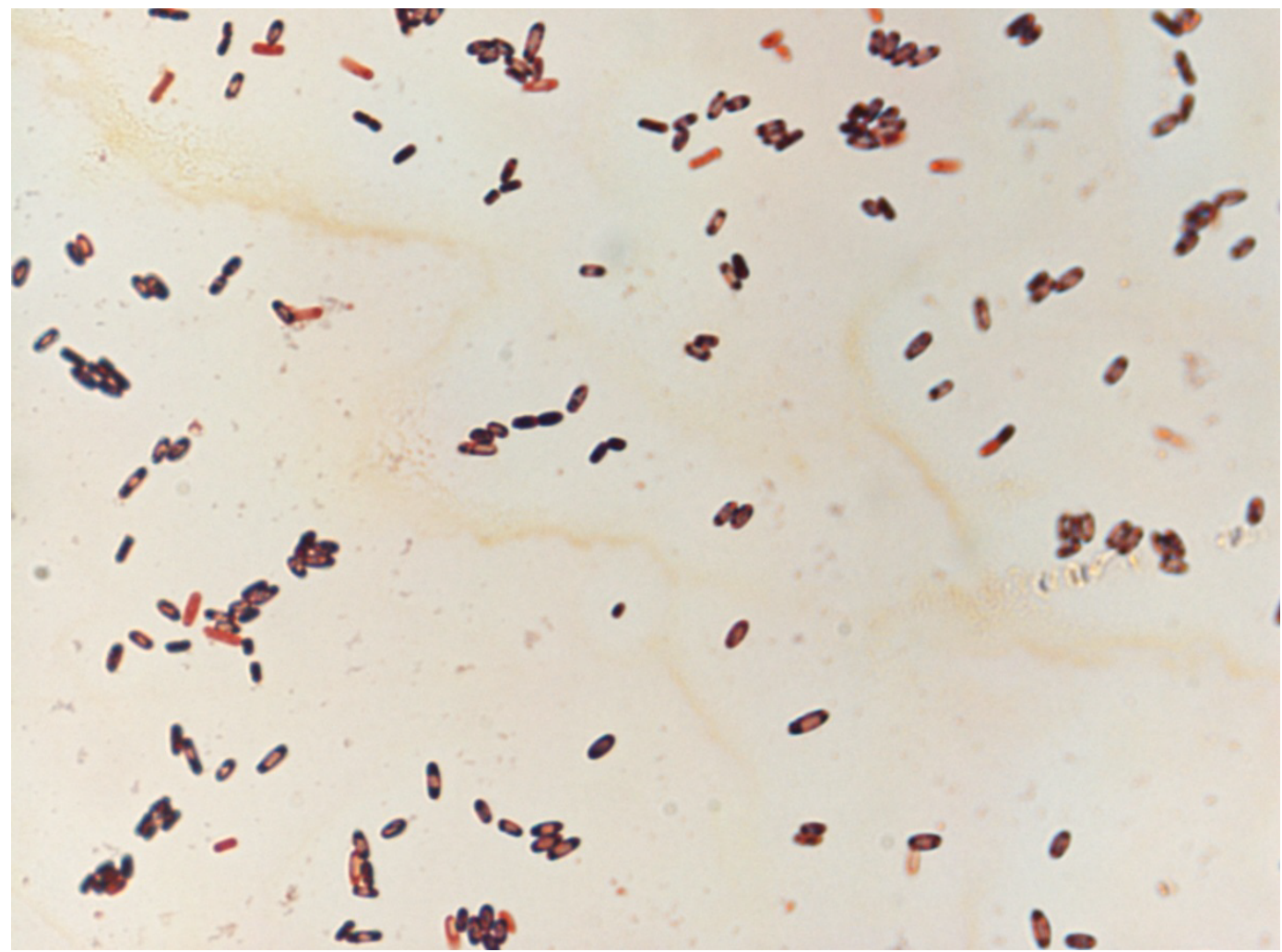

Figure 2. Gram staining of $C$. dakarense sp. nov. strain FF1 $1^{\top}$.

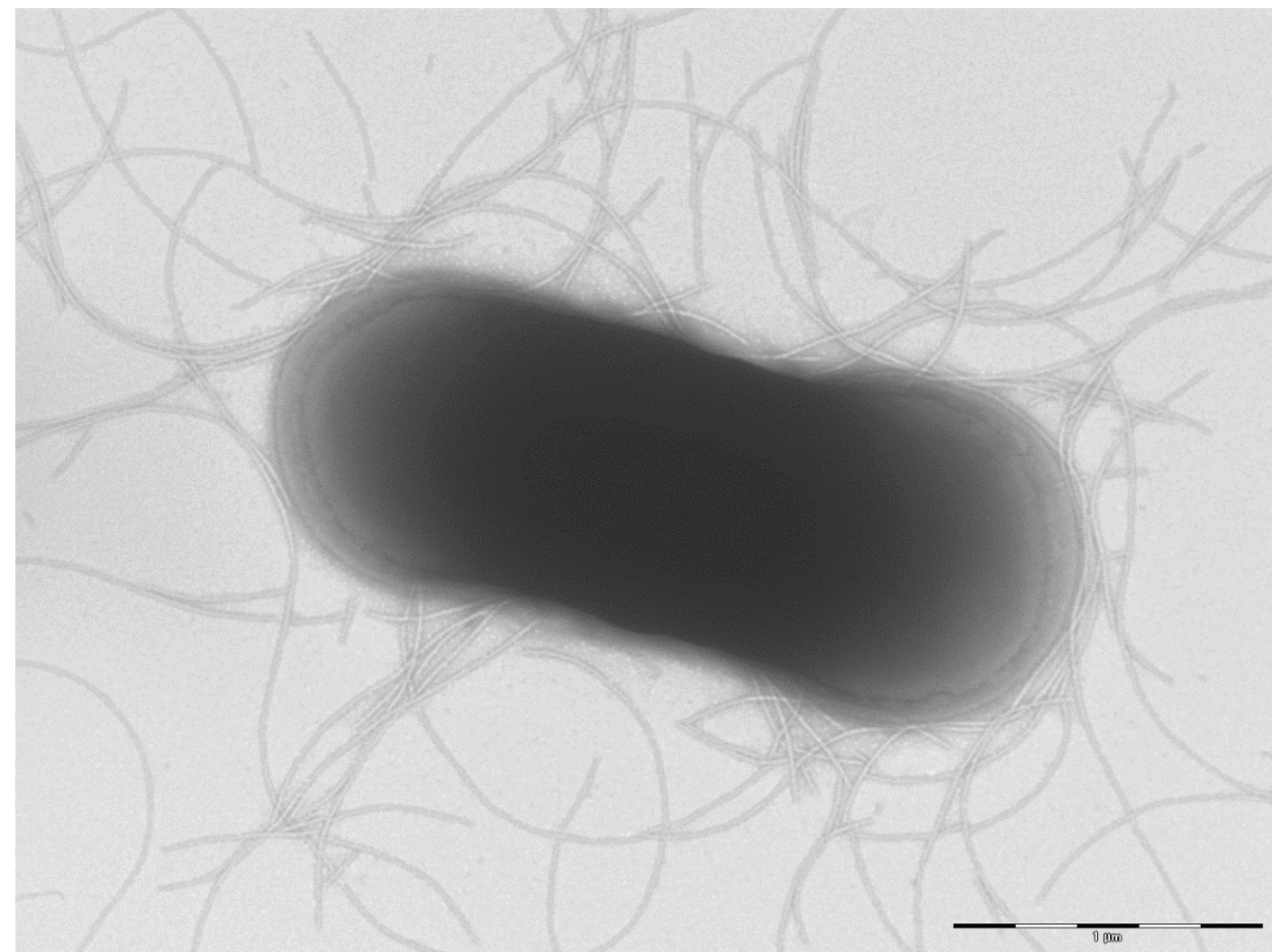

Figure 3. Transmission electron microscopy of $C$. dakarense sp. nov. strain $\mathrm{FF}^{\top}{ }^{\top}$, using a Morgani 268D (Philips) at an operating voltage of $60 \mathrm{kV}$. The scale bar represents $1 \mu \mathrm{m}$. 
Clostridium dakarense sp. nov.

Table 2. Differential characteristics of $C$. dakarense sp. nov. strain $\mathrm{FF} 1^{\top}$ (Cda)

\begin{tabular}{|c|c|c|c|c|c|c|c|c|c|c|}
\hline Properties & CDa & CBa & CBe & $\mathrm{CC}$ & CDi & CG & $\mathbf{C P}$ & CSa & CSe & CT \\
\hline Cell diameter $(\mu \mathrm{m})$ & 1.2 & 1.5 & 1.7 & 2.5 & 3.0 & $0.4-1.0$ & 1.3 & 3.0 & 1.1 & 2.5 \\
\hline $\begin{array}{l}\text { Oxygen } \\
\text { requirement }\end{array}$ & - & - & - & - & - & - & - & - & - & na \\
\hline Pigment production & - & - & - & - & + & + & + & na & - & + \\
\hline Gram stain & + & + & V & - & + & & + & - & + & - \\
\hline Salt requirement & - & na & na & na & na & - & - & na & - & na \\
\hline Motility & + & - & + & - & + & + & - & - & + & - \\
\hline $\begin{array}{l}\text { Endospore } \\
\text { formation }\end{array}$ & + & + & + & + & + & + & w & + & + & + \\
\hline \multicolumn{11}{|l|}{ Production of } \\
\hline Acid phosphatase & + & + & na & na & na & na & + & na & na & na \\
\hline Catalase & - & - & - & - & na & na & na & na & - & na \\
\hline Oxidase & - & na & na & na & na & na & na & na & - & na \\
\hline Nitrate reductase & - & - & - & na & - & - & + & + & - & - \\
\hline Urease & - & - & - & na & na & na & na & na & - & na \\
\hline$\beta$-galactosidase & - & + & na & na & na & - & + & na & - & na \\
\hline \multicolumn{11}{|l|}{ Acid from } \\
\hline L-Arabinose & - & na & + & - & - & - & - & + & na & na \\
\hline Ribose & - & + & - & & - & - & + & w & na & na \\
\hline Mannose & - & - & + & & + & - & + & na & na & na \\
\hline Mannitol & - & + & + & + & + & - & - & w & na & na \\
\hline Sucrose & - & + & + & + & + & - & + & w & na & na \\
\hline D-glucose & + & + & + & + & na & + & + & & na & na \\
\hline D-fructose & - & + & + & + & + & + & + & + & na & na \\
\hline D-maltose & + & + & + & + & - & + & + & w & na & na \\
\hline D-lactose & - & na & + & + & - & - & + & w & na & na \\
\hline \multicolumn{11}{|l|}{ Hydrolysis of } \\
\hline Gelatin & na & - & + & - & na & - & na & na & na & + \\
\hline Starch & na & na & + & - & - & - & + & - & na & \\
\hline $\begin{array}{l}\mathrm{G}+\mathrm{C} \text { content } \\
(\mathrm{mol} \%)\end{array}$ & 27.98 & 29.8 & 28 & 27 & 28 & 29 & 27 & 28 & 26.8 & 39 \\
\hline Habitat & $\begin{array}{c}\text { Human } \\
\text { gut }\end{array}$ & $\begin{array}{c}\text { Human } \\
\text { gut }\end{array}$ & $\begin{array}{c}\text { Human } \\
\text { gut }\end{array}$ & $\begin{array}{l}\text { Poplar } \\
\text { wood }\end{array}$ & $\begin{array}{c}\text { Human } \\
\text { gut }\end{array}$ & $\begin{array}{c}\text { Mud, } \\
\text { wastewater }\end{array}$ & $\begin{array}{c}\text { Colonic } \\
\text { flora }\end{array}$ & $\begin{array}{l}\text { Sewage } \\
\text { sludge }\end{array}$ & $\begin{array}{c}\text { Human } \\
\text { gut }\end{array}$ & $\begin{array}{c}\text { Sewage } \\
\text { sludge }\end{array}$ \\
\hline
\end{tabular}

C. bartlettii (CBa), C. beijerinckii (CBe), C. cellulovorans (CC), C. difficile (CDi), C. glycolicum (CG), C. perfringens (CP), C. saccharolyticum (CSa), C. senegalense (CSe) and C. thermocellum (CT).

$\mathrm{na}=$ data not available; $\mathrm{w}=$ weak, $\mathrm{v}=$ variable reaction 
Matrix-assisted laser-desorption/ionization timeof-flight (MALDI-TOF) MS protein analysis was carried out as previously described [31]. Briefly, a pipette tip was used to pick one isolated bacterial colony from a culture agar plate, and to spread it as a thin film on a MTP 384 MALDI-TOF target plate (Bruker Daltonics, Leipzig, Germany). Eighteen distinct deposits were made for strain $\mathrm{FF}^{\mathrm{T}}$ from eighteen isolated colonies. Each smear was overlaid with $2 \mu \mathrm{L}$ of matrix solution (saturated solution of alpha-cyano-4-hydroxycinnamic acid) in $50 \%$ acetonitrile, $2.5 \%$ tri-fluoracetic-acid, and allowed to dry for five minutes. Measurements were performed with a Microflex spectrometer (Bruker). Spectra were recorded in the positive linear mode for the mass range of 2,000 to 20,000 Da (parameter settings: ion source 1 (IS1), $20 \mathrm{kV}$; IS2, $18.5 \mathrm{kV}$; lens, $7 \mathrm{kV}$ ). A spectrum was obtained after 675 shots at a variable laser power. The time of acquisition was between 30 seconds and $1 \mathrm{mi}-$ nute per spot. The eighteen spectra were imported into the MALDI BioTyper software (version 2.0,
Bruker) and analyzed by standard pattern matching (with default parameter settings) against the main spectra of 4,706 bacteria including 216 spectra from validly published species of Clostridium, that are part of the reference data contained in the BioTyper database. The method of identification included the $\mathrm{m} / \mathrm{z}$ from 2,000 to $20,000 \mathrm{Da}$. For every spectrum, 100 peaks at most were taken into account and compared with spectra in the database. A score enabled the identification, or not, from the tested species: a score $>2$ with a validly published species enabled the identification at the species level, and a score $<1.7$ did not enable any identification at the genus level. For strain $\mathrm{FF}^{\mathrm{T}}{ }^{\mathrm{T}}$, the maximal obtained score was lower than 1.9 , thus suggesting that our isolate was not a member of a known species. We added the spectrum from strain $\mathrm{FF}^{\mathrm{T}}$ to our database for future reference (Figure 4). Finally, the gel view allows us to highlight the spectrum differences with other members of the genus Clostridium (Figure 5).

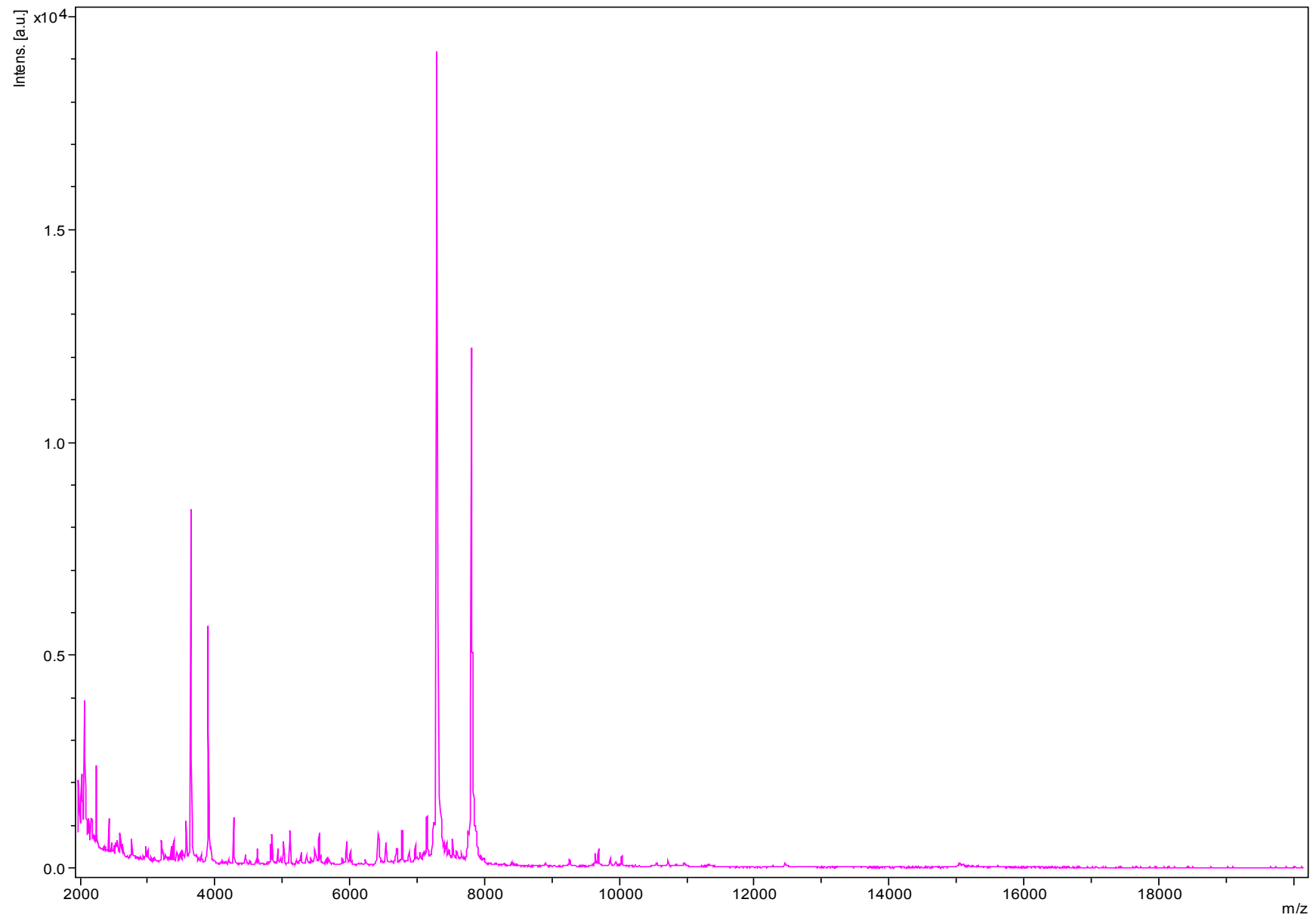

Figure 4. Reference mass spectrum from $C$. dakarense strain $\mathrm{FF}^{\top}{ }^{\top}$. Spectra from 18 individual colonies were compared and a reference spectrum was generated. 


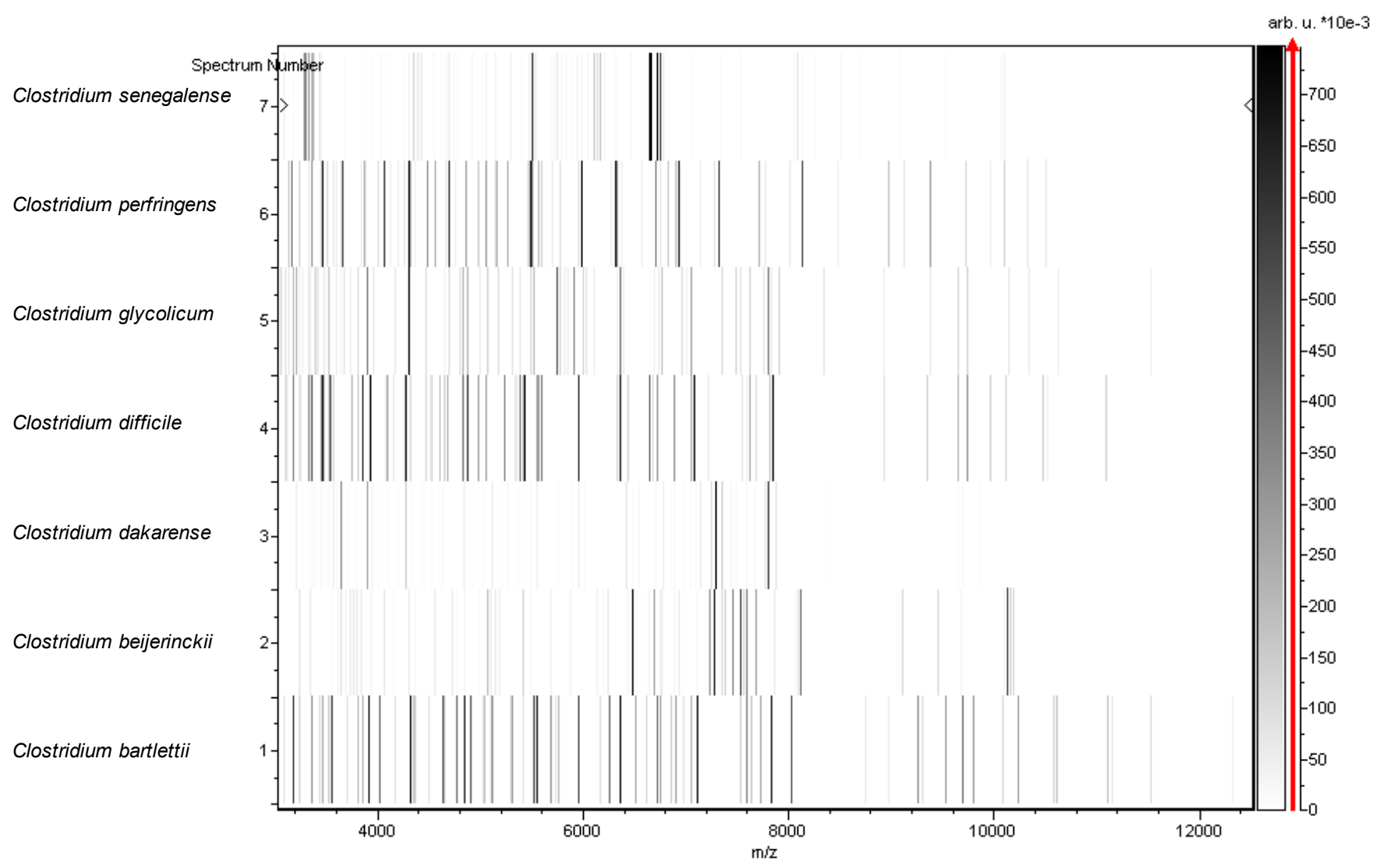

Figure 5. Gel view comparing C. dakarense sp. nov. strain FF1 ${ }^{\top}$ spectra with other members of the Clostridium genus (C. bartlettii, C. beijerinckii, C. difficile, C. glycolicum, C. perfringens, C. senegalense). The Gel View displays the raw spectra of all loaded spectrum files arranged in a pseudo-gel like look. The $x$-axis records the $\mathrm{m} / \mathrm{z}$ value. The left $y$-axis displays the running spectrum number originating from subsequent spectra loading. The peak intensity is expressed by a Gray scale scheme code. The color bar and the right y-axis indicate the relation between the color a peak is displayed with and the peak intensity in arbitrary units.

\section{Genome sequencing information}

\section{Genome project history}

The organism was selected for sequencing on the basis of its phylogenetic position and 16S rRNA similarity to other members of the genus Clostridium, and is part of a "culturomics" study of the human digestive flora aiming at isolating all bacterial species within human feces. It was the $94^{\text {th }}$ genome of a Clostridium species and the first genome of Clostridium dakarense sp. nov. The Genbank accession number is CBTZ00000000 and consists of 257 contigs. Table 3 shows the project information and its association with MIGS version 2.0 compliance [32].

\section{Growth conditions and DNA isolation}

C. dakarense sp. nov. strain $\mathrm{FF}^{\mathrm{T}}{ }^{\mathrm{T}}$ (= CSUR P243 = DSM 27086), was grown anaerobically on sheep blood-enriched Columbia agar medium at $37^{\circ} \mathrm{C}$. Eight petri dishes were spread and resuspended in $4 \times 100 \mu l$ of G2 buffer (EZ1 DNA Tissue kit, Qiagen). A first mechanical lysis was performed by glass powder on the Fastprep-24 device (Sample Preparation system) from MP Biomedicals, USA) using $2 \times 20$ seconds cycles. DNA was then treated with $2.5 \mu \mathrm{g} / \mu \mathrm{L}$ lysozyme (30 minutes at $37^{\circ} \mathrm{C}$ ) and extracted through the BioRobot EZ 1 Advanced XL (Qiagen). The DNA was then concentrated and purified on a Qiamp kit (Qiagen). DNA concentration was $70.7 \mathrm{ng} / \mu \mathrm{l}$ as determined by the Genios Tecan fluorometer, using the Quant-it Picogreen kit (Invitrogen). 


\begin{tabular}{lll}
\multicolumn{2}{l}{ Table 3. Project information } & \\
\hline MIGS ID & Property & Term \\
\hline MIGS-31 & Finishing quality & One 454 paired end 3-kb library \\
MIGS-28 & Libraries used & 454 GS FLX Titanium \\
MIGS-29 & Sequencing platforms & 35 \\
MIGS-31.2 & Fold coverage & Newbler version 2.5.3 \\
MIGS-30 & Assemblers & Prodigal \\
MIGS-32 & Gene calling method & CBTZ00000000 \\
& Genbank ID & \\
& Genbank Date of Release & \\
MIGS-13 & Project relevance & Study of the human gut microbiome \\
\hline
\end{tabular}

\section{Genome sequencing and assembly}

This project was loaded twice on a $1 / 4$ region for the paired-end application and once on a $1 / 8$ region for the shotgun on PTP Picotiterplates. The shotgun library was constructed with $500 \mathrm{ng}$ of DNA as described by the manufacturer (Roche) with the GS Rapid library Prep kit. For the pairedend sequencing, $5 \mu \mathrm{g}$ of DNA was mechanically fragmented on the Hydroshear device (Digilab, Holliston, MA, USA) with an enrichment size of 3$4 \mathrm{~kb}$. The DNA fragmentation was visualized using an Agilent 2100 BioAnalyzer on a DNA labchip 7500 , which yield an optimal size of $3.6 \mathrm{~kb}$. The library was constructed according to the 454_Titanium paired-end protocol and manufacturer. Circularization and nebulization were performed and generated a pattern with an optimum at $561 \mathrm{bp}$. After PCR amplification through $15 \mathrm{cy}$ cles followed by double size selection, the single stranded paired end library was then quantified with Quant-it Ribogreen kit (Invitrogen) on the Genios_Tecan fluorometer at $52 \mathrm{pg} / \mu \mathrm{L}$. The library concentration equivalence was calculated as $1.7 \mathrm{E}+08$ molecules $/ \mu \mathrm{L}$. The library was stored at $20^{\circ} \mathrm{C}$ until use.

The shotgun library was clonally amplified with $3 c p b$ in 3 emPCR reactions and the paired end library was amplified with lower cpb (1cpb) in 4 emPCR reactions with the GS Titanium SV emPCR Kit (Lib-L) v2. The yield of the emPCR was $5.37 \%$ for the shotgun reads and $19.27 \%$ for the pairedend reads, according to the quality expected by the range of 5 to $20 \%$ from the Roche procedure. A total of 340,000 beads from the $1 / 8$ region of the shotgun reads and 790,000 beads from the $1 / 4$ region of the paired-end reads were loaded on the GS Titanium PicoTiterPlates (PTP Kit 70×75) and sequenced with the GS Titanium Sequencing Kit XLR70.

The runs were performed overnight and then analyzed on the cluster through the gsRunBrowser and gsAssembler_Roche. The global 383,079 passed filter sequences generated $96.50 \mathrm{Mb}$ with a length average of $277 \mathrm{bp}$. These sequences were assembled using the Newbler software from Roche with $90 \%$ identity and $40 \mathrm{bp}$ as overlap. Fourteen scaffolds and 257 large contigs (>1500bp) were obtained, for a genome size of 3,735,762 bp.

\section{Genome annotation}

Open Reading Frames (ORFs) were predicted using Prodigal [33] with default parameters but the predicted ORFs were excluded if they spanned a sequencing gap region. The predicted bacterial protein sequences were searched against the GenBank database [34] and the Clusters of Orthologous Groups (COG) databases using BLASTP. The tRNAScanSE tool [35] was used to find tRNA genes, whereas ribosomal RNAs were found by using RNAmmer [36] and BLASTn against the GenBank database. Lipoprotein signal peptides and numbers of transmembrane helices were predicted using SignalP [37] and TMHMM [38] respectively. ORFans were identified if their BLASTP $E$-value was lower than $1 \mathrm{e}^{-03}$ for alignment length greater than 80 amino acids. If alignment lengths 
were smaller than 80 amino acids, we used an $E$ value of $1 \mathrm{e}-05$. Such parameter thresholds have already been used in previous works to define ORFans. Artemis [39] was used for data management and DNA Plotter [40] was used for visualization of genomic features. Mauve alignment tool was used for multiple genomic sequence alignment and visualization [41].

To estimate the mean level of nucleotide sequence similarity at the genome level between $C$. dakarense and nine other members of the genus Clostridium (Table 6), we use the Average Genomic Identity of gene Sequences (AGIOS) homemade software. Briefly, this software combines the Proteinortho software [42] for detecting orthologous proteins between genomes compared two by two, then retrieves the corresponding genes and determines the mean percentage of nucleotide sequence identity among orthologous ORFs using the Needleman-Wunsch global alignment algorithm. Clostridium dakarense strain $\mathrm{FF}^{\mathrm{T}}$, was compared to C. bartlettii strain DSM 16795 (GenBank accession number NZ_DS499569), C. beijerinckii strain NCIMB 8052 (NC_009617), C. cellulovorans strain 743B (NC_014393), C. difficile strain 630 (NC8009089), C. glycolicum strain ATCC 14880 (ARES01000000), C. perfringens strain ATCC 13124 (BA000016), C. saccharolyticum strain WM1 (NC_014376), C. senegalense strain JC122 ${ }^{\mathrm{T}}$ (CAEV00000000), and $C$. thermocellum strain ATCC 27405 (CP000568).

\section{Genome properties}

The genome of $C$. dakarense sp. nov. strain $\mathrm{FF} 1^{\mathrm{T}}$ is $3,735,762$ bp long (1 chromosome, but no plasmid) with a 27,98\% G + C content of (Figure 6 and Table 4). Of the 3,916 predicted genes, 3,843 protein-coding genes, and 73 were RNAs. Eight rRNA genes (one $16 \mathrm{~S}$ rRNA, one $23 \mathrm{~S}$ rRNA and six $5 \mathrm{~S}$ rRNA) and 65 predicted tRNA genes were identified in the genome. A total of 2,769 genes (72.05\%) were assigned a putative function (by COG or NR blast). Two hundred ninety-eight genes were identified as ORFans (7.75\%). The remaining 515 genes were annotated as hypothetical proteins $(13,40 \%)$. The distribution of genes into COGs functional categories is presented in Table 4. The properties and the statistics of the genome are summarized in Tables 4 and 5.

Table 4. Nucleotide content and gene count levels of the genome.

\begin{tabular}{lrr}
\hline Attribute & Value & \% of total \\
\hline Genome size (bp) & $3,735,762$ & 100 \\
DNA coding region (bp) & $3,239,020$ & 86.70 \\
DNA G+C content (bp) & $1,045,424$ & 27.98 \\
Total genes & 3,916 & 100 \\
RNA genes & 73 & 1.86 \\
Protein-coding genes & 3,843 & 98.14 \\
Genes with function prediction & 2,769 & 72.05 \\
Genes assigned to COGs & 2,849 & 74.13 \\
Genes with peptide signals & 410 & 10.67 \\
Genes with transmembrane helices & 1,016 & 26.44 \\
\hline
\end{tabular}

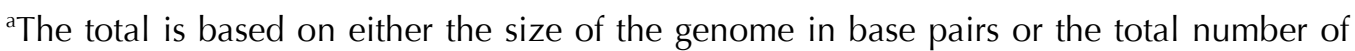
protein coding genes in the annotated genome 


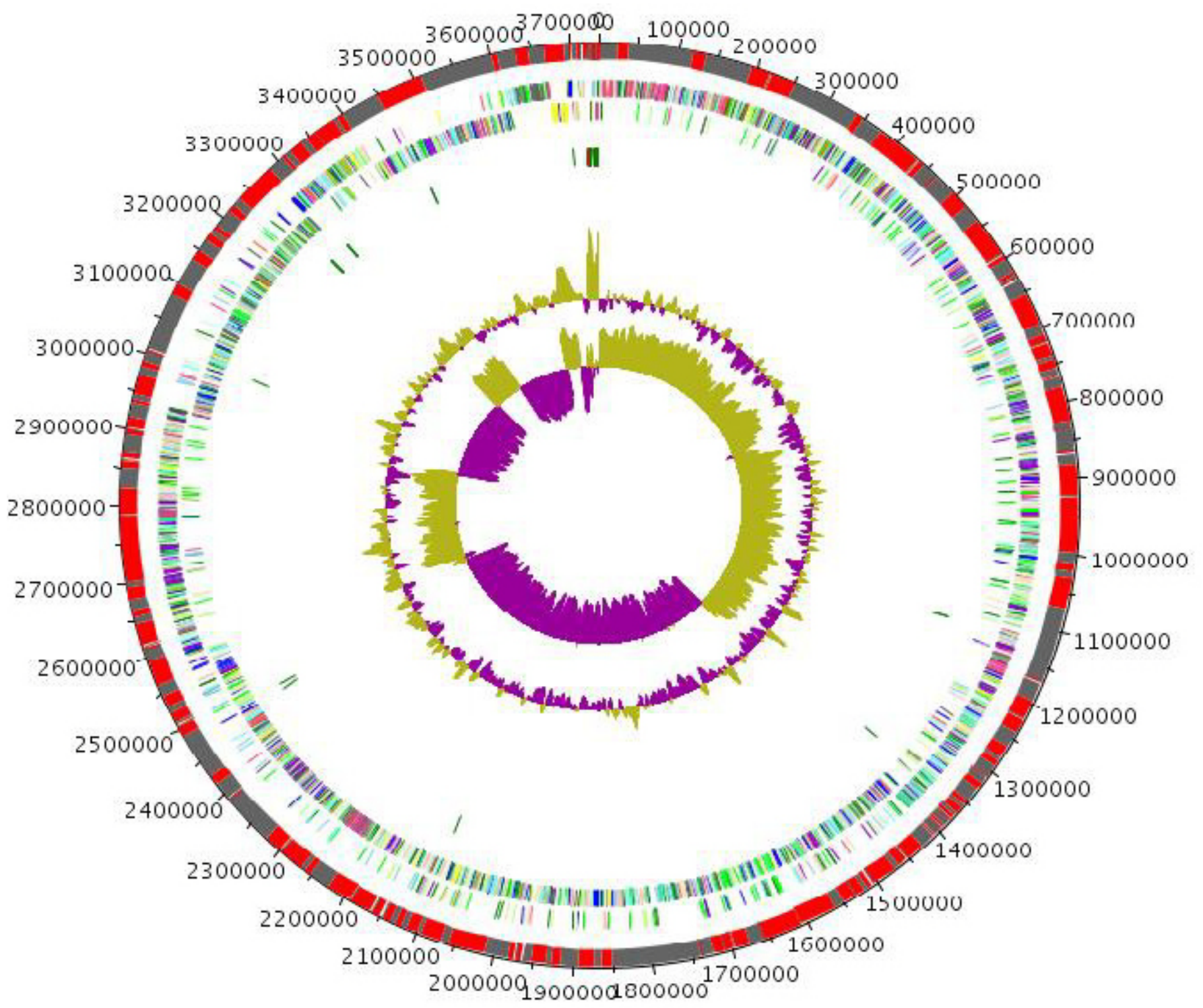

Figure 6. Graphical circular map of the chromosome. From the outside in, the outer two circles show open reading frames oriented in the forward and reverse directions (colored by COG categories), respectively. The third circle marks the rRNA gene operon (red) and tRNA genes (green). The fourth circle shows the $\mathrm{G}+\mathrm{C} \%$ content plot. The inner-most circle shows the GC skew, purple and olive indicating negative and positive values, respectively.

\section{Comparison with the genomes from other Clostridium species}

The genome sequence of Clostridium sp. is currently available for more than seventy-five Clostridium species. Here we compared the genome sequence of $C$. dakarense strain $\mathrm{FF}^{\mathrm{T}}$ with than those of $C$. bartlettii, C. beijerinckii, C. cellulovorans, C. difficile, C. glycolicum, C. perfringens, C. saccharolyticum, C. senegalense, and $C$. thermocellum.

The draft genome sequence of $C$. dakarense strain FF1 ${ }^{\mathrm{T}}$ is smaller than those of $C$. cellulovorans, $C$. beijerinckii, C. senegalense, C. saccharolyticum, $C$. thermocellum, C. difficile, C. glycolicum (3.73, 5.26,
$6.0,3.89,4.66,3.84,4.3$ and $3.99 \mathrm{Mb}$, respectively) but larger than those of $C$. perfringens and $C$. bartletii (3.26 and $2.97 \mathrm{Mb}$, respectively). The $\mathrm{G}+\mathrm{C}$ content of $C$. dakarense is lower than those of $C$. cellulovorans, C. beijerinckii, C. perfringens, $C$. saccharolyticum, C. thermocellum, C. difficile (31.2, $29.9,28.4,45,39$ and 29.1\%, respectively) but higher than those of C. bartlettii, C. glycolicum and C. senegalense (28.8, 28 and 26.8\%, respectively). The gene content of $C$. dakarense is larger than those of C. thermocellum, C. senegalense, C. 
perfringens, C. glycolicum, C. bartlettii $(3,916$, $3,173,3,761,2,876,3,840$ and 2,787 , respectively) and smaller than those of C. cellulovorans, $C$. beijerinckii, C. saccharolyticum and C. difficile, (4,501, 5,243, 4,154 and 4,019, respectively). The ratio of genes per $\mathrm{Mb}$ of $C$. dakarense is larger to those of C. cellulovorans, C. beijerinckii, C. senegalense, $C$. saccharolyticum, $C$. thermocellum, $C$. difficile, C. bartlettii, C. glycolicum and C. perfringens $(1,049,856,874,966,891,826,934$, 938, 962 and 882, respectively).

The number of orthologous genes shared between C. dakarense and other compared Clostridium species has been summarized in Table 6 . The average percentage of nucleotide sequence identity ranged from 62.05 to $74.5 \%$ among previously published Clostridium species, and from 61.94 to $75.7 \%$ between $C$. dakarense and other studied Clostridium species, thus confirming its new species status.

Table 5. Number of genes associated with the 25 general COG functional categories.

\begin{tabular}{crrl}
\hline Code & Value & \%age & Description \\
J & 171 & 4.45 & Translation \\
A & 0 & 0 & RNA processing and modification \\
K & 325 & 8.46 & Transcription \\
L & 158 & 4.11 & Replication, recombination and repair \\
B & 1 & 0.03 & Chromatin structure and dynamics \\
D & 34 & 0.88 & Cell cycle control, mitosis and meiosis \\
Y & 0 & 0 & Nuclear structure \\
V & 111 & 2.89 & Defense mechanisms \\
T & 225 & 5.85 & Signal transduction mechanisms \\
M & 165 & 4.29 & Cell wall/membrane biogenesis \\
N & 58 & 1.51 & Cell motility \\
Z & 0 & 0 & Cytoskeleton \\
W & 0 & 0 & Extracellular structures \\
U & 45 & 1.17 & Intracellular trafficking and secretion \\
O & 95 & 2.47 & Posttranslational modification, protein turnover, chaperones \\
C & 194 & 5.04 & Energy production and conversion \\
G & 248 & 6.45 & Carbohydrate transport and metabolism \\
E & 248 & 6.45 & Amino acid transport and metabolism \\
F & 88 & 2.29 & Nucleotide transport and metabolism \\
H & 117 & 3.04 & Coenzyme transport and metabolism \\
I & 72 & 1.87 & Lipid transport and metabolism \\
P & 181 & 4.71 & Inorganic ion transport and metabolism \\
Q & 52 & 1.35 & Secondary metabolites biosynthesis, transport and catabolism \\
R & 386 & 10.04 & General function prediction only \\
S & 261 & 6.79 & Function unknown \\
- & 994 & 25.87 & Not in COGs \\
\hline & & & \\
\hline
\end{tabular}

a The total is based on the total number of protein coding genes in the annotated genome. 
Table 6. Numbers of orthologous proteins shared between genomes (upper right)

\begin{tabular}{llllllllllll}
\hline & CDa & CC & CBe & CP & CSe & CSa & CT & CBa & CG & CDi \\
\hline CDa & $\mathbf{3 , 8 0 8}$ & 1,045 & 1,230 & 1,089 & 1,131 & 1,013 & 806 & 1,324 & 1,690 & 1,203 \\
CC & 68.22 & $\mathbf{4 , 2 5 4}$ & 1,490 & 1,163 & 1,181 & 1,057 & 967 & 871 & 1,038 & 1,021 \\
& & & & & & & & & & \\
CBe & 68.84 & 70.36 & $\mathbf{5 , 0 2 0}$ & 1,300 & 1,289 & 1,207 & 968 & 989 & 1,204 & 1,129 \\
CP & 70.02 & 70.43 & 72.15 & $\mathbf{2 , 6 6 0}$ & 1,168 & 920 & 777 & 845 & 1,005 & 1,147 \\
CSe & 69.91 & 70.37 & 70.82 & 70.13 & $\mathbf{3 , 7 0 4}$ & 930 & 821 & 856 & 1,134 & 1,008 \\
CSa & 61.94 & 62.50 & 62.44 & 62.22 & 62.05 & $\mathbf{4 , 1 5 4}$ & 854 & 833 & 1,004 & 998 \\
& & & & & & & & & & \\
CT & 64.49 & 64.84 & 64.56 & 64.78 & 64.53 & 63.83 & $\mathbf{3 , 1 7 3}$ & 713 & 840 & 952 \\
& & & & & & & & & & \\
CBa & 74.98 & 68.22 & 68.84 & 69.46 & 69.52 & 62.15 & 64.73 & $\mathbf{2 , 7 8 7}$ & 1,517 & 1,303 \\
CG & 75.70 & 68.28 & 68.83 & 69.49 & 69.57 & 62.26 & 64.59 & 76.04 & $\mathbf{3 , 8 4 0}$ & 1,568 \\
& & & & & & & & & & \\
CDi & 71.34 & 69.57 & 68.52 & 71.52 & 65.49 & 66.37 & 64.32 & 74.45 & 74.50 & $\mathbf{3 , 7 9 8}$ \\
\hline
\end{tabular}

average percentage similarity of nucleotides corresponding to orthologous protein shared between genomes (lower left) and numbers of proteins per genome (bold). CDa: C. dakarense; CC: C. cellulovorans; CBe: C. beijerinckii; CP: C. perfringens; CSe: C. senegalense; CSa: C. saccharolyticum; CT: C. thermocellum; CBa: C. bartlettii; CG: C. glycolicum; CDi: C. difficile.

\section{Conclusion}

On the basis of phenotypic, phylogenetic and genomic analyses, we formally propose the creation of Clostridium dakarense sp. nov. which contains strain $\mathrm{FF} 1^{\mathrm{T}}$. This bacterium strain has been isolated from the fecal flora of a 4-months-old Senegalese child suffering from gastroenteritis.

\section{Description of Clostridium senegalense sp. nov.}

Clostridium dakarense (da.kar.e'n.se. L. gen. neutr. $\mathrm{n}$. dakarense, pertaining to, or originating from Dakar, the capital of Senegal, where the type strain was isolated).

Colonies were $1.5 \mathrm{~mm}$ in diameter on bloodenriched Columbia agar and Chocolate agar + PolyViteX. Cells are rod-shaped with a mean diameter of $1.2 \mu \mathrm{m}$. Optimal growth is achieved anaerobically. No growth is observed in aerobic conditions. Growth occurs between $25-37^{\circ} \mathrm{C}$, with optimal growth observed at $37^{\circ} \mathrm{C}$, in medium $5 \%$ sheep blood-enriched Columbia agar. Cells stain Gram-positive, are endospore-forming, and motile. Catalase, oxidase, urease, indole and nitrate reduction activity are absent. Arginine dihydrolase, Nacetyl- $\beta$-glucosanimidase and pyroglutamic acid arylamidase activity are present. Cells are susceptible to amoxicillin, metronidazole, vancomycin, imipenem and rifampicin but resistant to trimethoprim/sulfamethoxazole.

The $\mathrm{G}+\mathrm{C}$ content of the genome is $27.98 \%$. The $16 \mathrm{~S}$ rRNA gene sequence and whole-genome shotgun sequence of $C$. dakarense strain $\mathrm{FF} 1^{\mathrm{T}}$ (= CSUR P243 = DSM 27086) are deposited in GenBank under accession numbers KC517358 and CBTZ00000000, respectively. The type strain FF1 ${ }^{\mathrm{T}}$ (= CSUR P243 = DSM 27086) was isolated from the fecal flora of a 4-months-old child in Dakar, Senegal. 


\section{Acknowledgements}

The authors thank the Xegen Company (www.xegen.fr) for automating the genomic annotation process. This

\section{References}

1. Rossello-Mora R. DNA-DNA Reassociation Methods Applied to Microbial Taxonomy and Their Critical Evaluation. In: Stackebrandt E (ed), Molecular Identification, Systematics, and population Structure of Prokaryotes. Springer, Berlin, 2006, p. 23-50.

2. Stackebrandt E, Ebers J. Taxonomic parameters revisited: tarnished gold standards. Microbiol Today 2006; 33:152-155.

3. Welker M, Moore ER. Applications of whole-cell matrix-assisted laser-desorption/ionization timeof-flight mass spectrometry in systematic microbiology. Syst Appl Microbiol 2011; 34:2-11. PubMed http://dx.doi.org/10.1016/j.syapm.2010.11.013

4. Tindall BJ, Rosselló-Móra R, Busse HJ, Ludwig W, Kämpfer P. Notes on the characterization of prokaryote strains for taxonomic purposes. Int / Syst Evol Microbiol 2010; 60:249-266. PubMed http://dx.doi.org/10.1099/ijs.0.016949-0

5. Kokcha S, Mishra AK, Lagier JC, Million M, Leroy Q, Raoult D, Fournier PE. Non contiguousfinished genome sequence and description of $\mathrm{Ba}-$ cillus timonensis sp. nov. Stand Genomic Sci 2012; 6:346-355. PubMed http://dx.doi.org/10.4056/sigs.2776064

6. Lagier JC, El Karkouri K, Nguyen TT, Armougom F, Raoult D, Fournier PE. Non-contiguous finished genome sequence and description of Anaerococcus senegalensis sp. nov. Stand Genomic Sci 2012; 6:116-125. PubMed http://dx.doi.org/10.4056/sigs.2415480

7. Mishra AK, Gimenez G, Lagier JC, Robert C, Raoult D, Fournier PE. Non-contiguous finished genome sequence and description of Alistipes senegalensis sp. nov. Stand Genomic Sci 2012; 6:304-314. http://dx.doi.org/10.4056/sigs.2625821

8. Lagier JC, Armougom F, Mishra AK, Ngyuen TT, Raoult D, Fournier PE. Non-contiguous finished genome sequence and description of Alistipes timonensis sp. nov. Stand Genomic Sci 2012; 6:315-324. PubMed

9. Mishra AK, Lagier JC, Robert C, Raoult D, Fournier PE. Non-contiguous finished genome sequence and description of Clostridium senegalense sp. nov. Stand Genomic Sci 2012; 6:386-395. PubMed study was funded by the Mediterranee-Infection Foundation.

10. Mishra AK, Lagier JC, Robert C, Raoult D, Fournier PE. Non-contiguous finished genome sequence and description of Peptoniphilus timonensis sp. nov. Stand Genomic Sci 2012; 7:111. PubMed http://dx.doi.org/10.4056/sigs.2956294

11. Mishra AK, Lagier JC, Rivet R, Raoult D, Fournier $P E$. Non-contiguous finished genome sequence and description of Paenibacillus senegalensis sp. nov. Stand Genomic Sci 2012; 7:70-81. PubMed

12. Prazmowski A. "Untersuchung über die Entwickelungsgeschichte und Fermentwirking einiger Bakterien-Arten." Ph.D. Dissertation, University of Leipzig, Germany, 1880, p. 366-371.

13. List of prokaryotic names with standing with nomenclature. http://www.bacterio.net

14. Evaluations and Standards Laboratory. "Identification of Clostridium species", 2008 pp. 14.

15. Wells CL, Wilkins TD. (1996). Clostridia: Spore forming Anaerobic Bacilli In: Baron's Medical Microbiology (Baron $\mathrm{S}$ et al., eds.) (4th ed.). University of Texas Medical Branch.

16. Keis S, Shaheen R, David T. Jones Emended descriptions of Clostridium acetobutylicum and Clostridium beijerinckii, and descriptions of Clostridium saccharoperbutylacetonicum sp. nov. and Clostridium saccharobutylicum sp. nov. Int / Syst Evol Microbiol 2001; 51:2095-2103. PubMed http://dx.doi.org/10.1099/00207713-51-6-2095

17. Carnahan JE, Castle JE. Nitrogen Fixation. Annu Rev Plant Physiol 1963; 14:125-136. http://dx.doi.org/10.1146/annurev.pp.14.060163.00 $\underline{1013}$

18. Field D, Garrity G, Gray T, Morrison N, Selengut J, Sterk P, Tatusova T, Thomson N, Allen MJ, Angiuoli SV, et al. The minimum information about a genome sequence(MIGS) specification. Nat Biotechnol 2008; 26:541-547. PubMed http://dx.doi.org/10.1038/nbt1360

19. Woese CR, Kandler O, Wheelis ML. Towards a natural system of organisms: proposal for the domains Archae, Bacteria, and Eukarya. Proc Natl Acad Sci USA 1990; 87:4576-4579. PubMed http://dx.doi.org/10.1073/pnas.87.12.4576

20. Gibbons NE, Murray RGE. Proposals Concerning the Higher Taxa of Bacteria. Int / Syst Bacteriol 
1978; 28:1-6. http://dx.doi.org/10.1099/0020771328-1-1

21. Garrity GM, Holt JG. The Road Map to the Manual. In: Garrity GM, Boone DR, Castenholz RW (eds), Bergey's Manual of Systematic Bacteriology, Second Edition, Volume 1, Springer, New York, 2001, p. 119-169.

22. Murray RGE. The Higher Taxa, or, a Place for Everything...? In: Holt JG (ed), Bergey's Manual of Systematic Bacteriology, First Edition, Volume 1, The Williams and Wilkins Co., Baltimore, 1984, p. 31-34.

23. List of new names and new combinations previously effectively, but not validly, published. List no. 132. Int J Syst Evol Microbiol 2010; 60:469472. http://dx.doi.org/10.1099/ijs.0.022855-0

24. Rainey FA. Class II. Clostridia class nov. In: De Vos P, Garrity G, Jones D, Krieg NR, Ludwig W, Rainey FA, Schleifer KH, Whitman WB (eds), Bergey's Manual of Systematic Bacteriology, Second Edition, Volume 3, Springer-Verlag, New York, 2009, p. 736.

25. Skerman VBD, Sneath PHA. Approved list of bacterial names. Int / Syst Bacteriol 1980; 30:225420. http://dx.doi.org/10.1099/00207713-30-1-225

26. Prévot AR. In: Hauderoy P, Ehringer G, Guillot G, Magrou. J., Prévot AR, Rosset D, Urbain A (eds), Dictionnaire des Bactéries Pathogènes, Second Edition, Masson et Cie, Paris, 1953, p. 1-692.

27. Pribram E. Klassification der Schizomyceten. Klassifikation der Schizomyceten (Bakterien), Franz Deuticke, Leipzig, 1933, p. 1-143.

28. Smith LDS, Hobbs G. Genus III. Clostridium Prazmowski 1880, 23. In: Buchanan RE, Gibbons NE (eds), Bergey's Manual of Determinative Bacteriology, Eighth Edition, The Williams and Wilkins Co., Baltimore, 1974, p. 551-572.

29. Ashburner M, Ball CA, Blake JA, Botstein D, Butler H, Cherry JM, Davis AP, Dolinski K, Dwight SS, Eppig JT, et al. Gene ontology: tool for the unification of biology. The Gene Ontology Consortium. Nat Genet 2000; 25:25-29. PubMed http://dx.doi.org/10.1038/75556

30. Stackebrandt E, Ebers J. Taxonomic parameters revisited: tarnished gold standards. Microbiol Today 2006; 33:152-155.

31. Seng P, Drancourt M, Gouriet F, La Scola B, Fournier PE, Rolain JM, Raoult D. Ongoing revolution in bacteriology: routine identification of bacteria by matrix-assisted laser desorption ionization time-of-flight mass spectrometry. Clin In- fect Dis 2009; 49:543-551. PubMed

http://dx.doi.org/10.1086/600885

32. Field D, Garrity G, Gray T, Morrison N, Selengut J, Sterk P, Tatusova T, Thomson N, Allen MJ, Angiuoli SV, et al. The minimum information about a genome sequence (MIGS) specification. Nat Biotechnol 2008; 26:541-547. PubMed http://dx.doi.org/10.1038/nbt1360

33. Prodigal. http://prodigal.ornl.gov

34. GenBank database. http://www.ncbi.nlm.nih.gov/genbank

35. Lowe TM, Eddy SR. tRNAscan-SE: a program for improved detection of transfer RNA genes in genomic sequence. Nucleic Acids Res 1997; 25:955-964. PubMed

36. Lagesen K, Hallin P, Rodland EA, Staerfeldt HH, Rognes T, Ussery DW. RNAmmer: consistent and rapid annotation of ribosomal RNA genes. Nucleic Acids Res 2007; 35:3100-3108. PubMed http://dx.doi.org/10.1093/nar/gkm160

37. Bendtsen JD, Nielsen H, von Heijne G, Brunak S. Improved prediction of signal peptides: SignalP 3.0. J Mol Biol 2004; 340:783-795. PubMed http://dx.doi.org/10.1016/j.jmb.2004.05.028

38. Krogh A, Larsson B, von Heijne G, Sonnhammer EL. Predicting transmembrane protein topology with a hidden Markov model: application to complete genomes. J Mol Biol 2001; 305:567580. PubMed http://dx.doi.org/10.1006/jmbi.2000.4315

39. Rutherford K, Parkhill J, Crook J, Horsnell T, Rice P, Rajandream MA, Barrell B. Artemis: sequence visualization and annotation. Bioinformatics 2000; 16:944-945. PubMed http://dx.doi.org/10.1093/bioinformatics/16.10.944

40. Carver T, Thomson N, Bleasby A, Berriman M, Parkhill J. DNAPlotter: circular and linear interactive genome visualization. Bioinformatics 2009; 25:119-120. PubMed http://dx.doi.org/10.1093/bioinformatics/btn578

41. Darling AC, Mau B, Blattner FR, Perna NT. Mauve: multiple alignment of conserved genomic sequence with rearrangements. Genome Res 2004; 14:1394-1403. PubMed http://dx.doi.org/10.1101/gr.2289704

42. Lechner M, Findeib S, Steiner L, Marz M, Stadler PF, Prohaska SJ. Proteinortho: Detection of (Co)orthologs in large-scale analysis. BMC Bioinformatics $2011 ; \mathbf{1 2 : 1 2 4}$. PubMed http://dx.doi.org/10.1186/1471-2105-12-124 